\title{
EFFECT OF A DIABETOGENIC FACTOR FROM BOVINE ADENOHYPOPHYSIS ON DOG SERUM NEFA LEVELS
}

\author{
GENE F. TUTWILER* \\ Department of Biological Chemistry, University of Michigan, \\ Ann Arbor, Michigan, U.S.A. \\ (Received 30 June, 1972)
}

\begin{abstract}
1. Fasted dog serum non-esterified fatty acid (NEFA) levels were elevated to and 34 hours after administration of a diabetogenic protein (BDF) isolated from bovine adenohypophysis.

2. The fasting serum NEFA were elevated in spite of the presence of normal or high glucose and insulin levels.

3. After oral glucose administration to BDF-treated animals, a fall of serum NEFA paralleled inversely the increasing levels of blood glucose and serum insulin.

4. These data are discussed with respect to the insulin-antagonistic action of BDF. Even though the plasma NEFA fell in response to glucose in BDF-treated animals, the NEFA during the entire 3 -hour glucose-tolerance test were always significantly higher than the levels observed in the control tests.

5. Since BDF is similar to the diabetogenic protein isolated from the urine of patients with lipoatrophic diabetes, its lipid-mobilizing action might help to explain the lipoatrophy, hyperlipaemia, diabetes mellitus, and insulin resistance seen in lipoatrophic diabetic patients.
\end{abstract}

CRAtG and Miller ( 1960 ) have observed that in animals, anterior pituitary extracts can induce both diabetes mellitus and a mobilization of fat from adipose tissue. Therefore, it has been suggested that dysfunction of the anterior pituitary may be the cause of the syndrome of lipoatrophic diabetes. This syndrome is characterized by generalized complete lipoatrophy, hyperlipaemia, increased liver size, and diabetes mellitus with insulin resistance. At present, the nature of the pituitary principle involved is not known. It is not growth hormone, since Samaan and Craig (1969) have been unable to find an excessive secretion of this polypeptide in lipoatrophic diabetes patients.

* Present address: Department of Biochemical Research, McNeil Laboratories Inc., Camp Hill Road, Fort Washington. Pennsylvania 19034, U.S.A.

Supported in part by Grant GMoor87 from NIH to the Department of Biological Chemistry, University of Michigan.
Recently, a new diabetogenic protein has been isolated from bovine (Louis, Conn, and Minick, I965; I966) ovine, porcine (Louis and Conn, 1968), and human (Louis and Conn, 1972). pituitary glands. A similar protein has been isolated from the urine of patients with lipoatrophic diabetes (Louis and Conn, 1962; Louis and others, 1963 ; Louis, 1969) and diabetes mellitus patients with proteinuria (Louis and Conn, I969). Trygstad (1968) has noted the possible relationship of this factor to lipoatrophic diabetes and believes that the disorder is related to congenital generalized lipodystrophy. In addition, Marcus (1966) has noted the relationship of this factor to the lipoatrophic syndrome. He has postulated that the protein is a hypophyseal lipotrophic hormone and has stated that this action might help explain the nature of the disease.

The above facts have pointed to a lipidmetabolic activity in addition to the diabetogenic effect of this factor. A lipolytic effect of the bovine material had previously 
(Tutwiler, I97I) been postulated from the ability of acute doses to increase the total fat content of the livers of fasting intact rats. The present study demonstrates that the bovine diabetogenic factor is capable of increasing serum NEFA levels of dogs prior to and during glucose-tolerance tests. Previously, this bovine factor has been shown to have a 'glycostatic effect', but not a growth effect on hypophysectomized rats (Tutwiler and Louis, I97I); to induce hyperglycaemia and insulin resistance in men and dogs (Louis and others, 1966); and to induce concomitant hyperglycaemia and hyperinsulinaemia in normal dogs (Louis, Conn, and Appelt, 5971 ).

\section{MATERIALS AND METHODS}

Complete details of the glucose-tolerance test (GTT) procedures in dogs have been described elsewhere (Louis and others, 1971). The bovine diabetogenic factor (BDF) designated as fraction $P_{I}$ was isolated and dissolved by the procedure of Louis and others (1966). A more highly purified preparation (designated as pure BDF) was isolated by the method of Louis, Tutwiler, and Conn (1972). This material was used in two experiments. Bovine serum albumin (BSA, Fraction $\mathrm{V}$-Armour Co.) was dissolved in saline.

The effects of the bovine factor upon blood glucose, serum insulin, and serum NEFA were studied in 9 trained mongrel and beagle dogs (4 males and 5 females). The multiple injection test procedure was as follows: two control glucosetolerance tests were performed on days $I$ and 2 ; a subcutaneous injection of the bovine protein (fraction $\mathrm{PI}_{\mathrm{I}}$ ) ro hours before the third glucosetolerance test, which was carried out on day 3 ; administration of a single dose of the protein daily for 2 more days with glucose-tolerance tests being done on days 4 and $5 ;$ and a final glucose-tolerance test carried out 34 hours after the last injection of protein. Postinjection glucose-tolerance tests were carried out $1_{4}$ days after the last injection and at least 2 weeks were allowed to elapse between two sets of experiments.

In addition to these multiple injection studies a series of experiments was performed to observe the NEFA changes Io and 34 hours after only a single injection of $5-6 \mathrm{mg}$. per $\mathrm{kg}$. body-weight of fraction $\mathrm{P}_{1}$. In order to facilitate statistical comparisons between a large number of separate dog experiments having differing baseline values, the results of paired studies (control versus Io-hour GTT and control versus 34 -hour GTT) have been calculated as percentage changes. In some experiments bovine serum albumin was injected as a control. The methods for the estimation of blood glucose and serum insulin have been discussed elsewhere (Louis and others, 1971 ). Serum NEFA were measured by a modification of the method described by Dole and Meinertz. 1960 ).

\section{RESULTS}

A typical set of measurements of nonesterified fatty acids (NEFA), insulin, and glucose during oral glucose-tolerance tests after administration of increasing doses of fraction $\mathrm{PI}_{\mathrm{I}}$ are graphically presented in Fig. IA, B, C. Bovine diabetogenic factor (BDF) was capable of increasing the fasting serum NEFA to levels two or three times greater than controls in hours after injection. After the administration of glucose, an abnormal elevation in blood sugar and insulin occurred as well as a rapid fall of serum NEFA. By 2 hours after glucose administration there was a rise of NEFA and a fall of glucose and insulin. Fasting NEFA levels were still elevated at 34 hours, but 14 days after the last injection the values had returned to normal. Fig. 2 presents an additional example of the NEFA changes induced by increasing doses of fraction $\mathrm{Pl}_{\mathfrak{l}}$ during dog glucose-tolerance tests. It was noted in all studies that the rate of NEFA decline after oral glucose administration became slower after prolonged administration of BDF. These studies using multiple injections of fraction $P_{1}$ were repeated nine times with similar NEFA, glucose, and insulin results. The hyperglycaemic-hyperinsulinaemic response to $\mathrm{BDF}$ has been previously reported by Louis and others, (I97I).

Fig. 3 illustrates the plasma NEFA level variations induced in 18 -hour fasted dogs during a GTT 10 and 34 hours after a single treatment with fraction $\mathrm{Pl}$. A total of 24 separate experiments was performed. Fraction PI markedly increased the fasting NEFA levels 10 and 34 hours after only a single subcutaneous injection $(5-6 \mathrm{mg}$. per $\mathrm{kg}$. body-weight). Fig. 3 shows that the percentage change from control values of NEFA levels fell in response to oral glucose both 10 and 34 hours after injection. The levels reached during the entire 3 -hour GTT, however, were always significantly higher in 


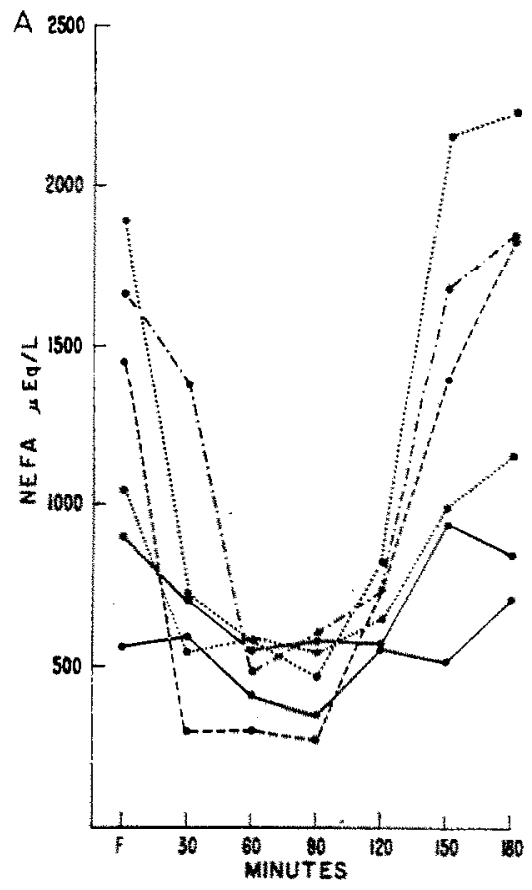

B 700
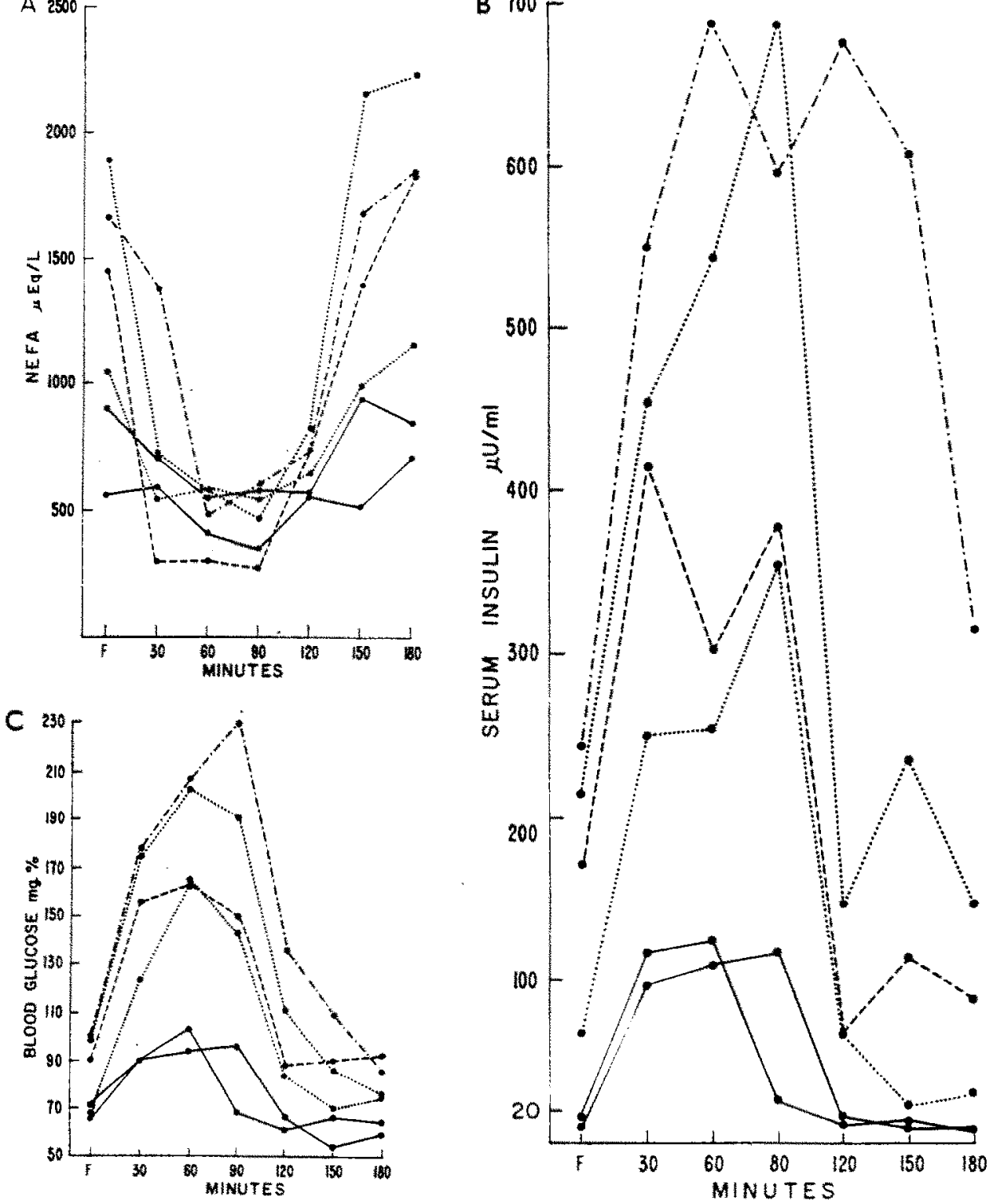

Fia. 1.-A, Effect of increasing doses of fraction $P_{1}$ on serum NEFA during oral glucose-tolerance tests in dog T. B, Effect of increasing doses of fraction $P_{1}$ on serum insulin during oral glucose-tolerance tests in $\operatorname{dog} \mathrm{T}, \mathrm{C}$, Effect of increasing doses of fraction $\mathrm{Pr}$ on blood glucose during oral glucose-tolerance tests in $\operatorname{dog} \mathrm{T}$. - , Control; $-\cdots,-$, , 10 hours after $4 \mathrm{mg}$. per kg.; . ., 10 hours after $5 \mathrm{mg}$. per $\mathrm{kg} . ;-\cdot-$, ro hours after $6 \mathrm{mg}$. per kg.; ..., postinjection ( 34 hours).

the treated group. NEFA levels were always back to control levels by 14 days after injection.
In addition, results from two experiments demonstrated that fasting serum NEFA were elevated twofold and glucose tolerance was 


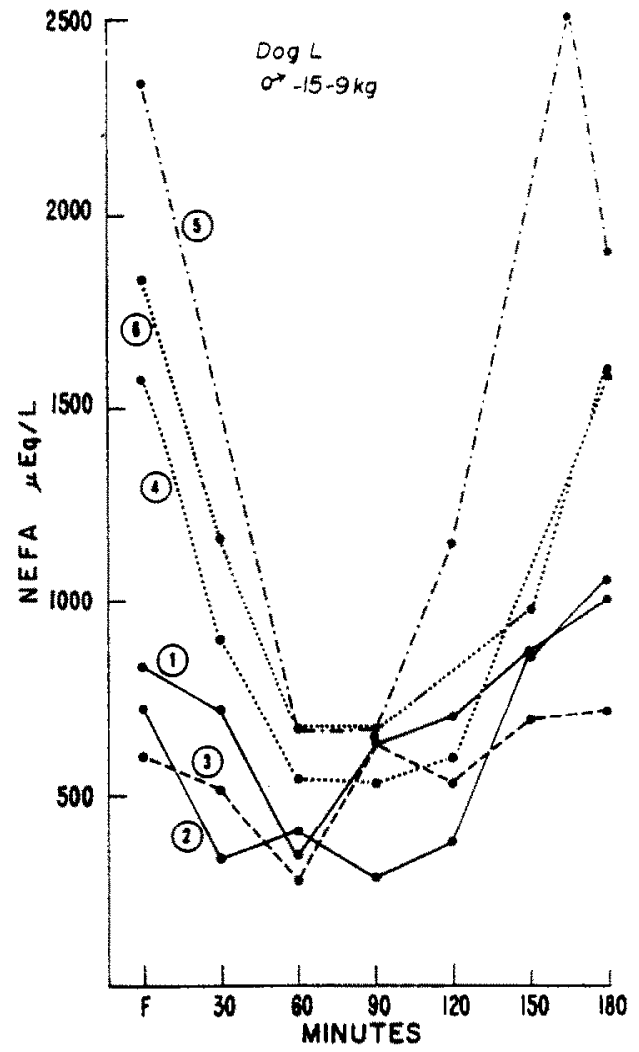

Fig. 2.-Effect of fraction $P_{I}$ upon serum NEFA levels during oral glucose-tolerance tests. Numbers in Fig. 2 refer to the following experimental conditions. 1. Control-14 days since last injection. 2. Control. 3. Ten hours after first injection-4 mg. per kg. 4. Ten hours after second injection $-5 \mathrm{mg}$. per $\mathrm{kg}$. 5. Ten hours after third injection-6 mg. per $\mathrm{kg}$. 6. Thirtyfour hours after third injection.

abnormal to hours after a single injection of $2 \mathrm{mg}$. of pure BDF per $\mathrm{kg}$. body-weight. Much larger amounts $(>3-4 \mathrm{mg}$. per $\mathrm{kg}$.) of fraction $\mathrm{PI}_{\mathrm{I}}$ were necessary in order to obtain comparable activity.

\section{DISCUSSION}

These studies clearly demonstrate that fasted dog serum NEFA levels are elevated 10 and 34 hours after administration of the diabetogenic factor isolated from bovine adenohypophysis. The fasting serum NEFA were elevated in spite of the presence of normal or high glucose and insulin levels.
This finding indicates that the bovine diabetogenic factor exerts antagonism to the NEFA-suppressing action of insulin, as well as to its hypoglycaemic action. The mechanism by which this protein acts is unknown; however, it is clear from our data that the results are not due to diminished concentrations of either serum insulin or blood glucose.

After oral glucose administration to BDF. treated animals, the fall in serum NEFA levels paralleled inversely the increasing levels of blood glucose and serum insulin. Hyperglycaemia alone has not been demonstrated to result in a lowering of NEFA levels

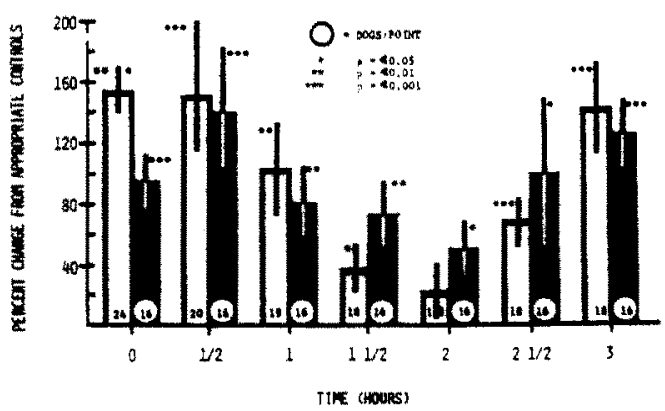

Fra. 3.-Effect of fraction $\mathrm{PI}_{\mathrm{I}}\left(\mathbf{j}^{-6} \mathrm{mg}\right.$. per kg. body-weight-s.c.) on plasma NEFA of I8-hour fasted dogs given glucose orally to hours (open bars) and 34 hours (solid bars) after treatment. (Dogs primed with $1 \times 75 \mathrm{~g}$. per $\mathrm{kg}$. glucose orally after o-time blood sample taken. Means $\pm S E M$ are shown. Significance in comparison to control glucose-tolerance tests determined by Student's i-test.)

in insulin-deficient animals (Laurell, 1956; Bierman, Dole, and Roberts, 1957). Insulin and glucose together, however, do induce a lowering of NEFA in diabetic subjects (Bierman and others, 1957). Consequently, both insulin and glucose are probably necessary for the observed fall of NEFA after glucose administration to our dogs. It appears, therefore, that the insulin-antagonistic action of BDF cannot be explained simply as a chemical neutralization of insulin, since it is obvious that insulin is probably responsible for the precipitous fall of NEFA. 


\section{ACKNOWLEDGMENT}

I would like to thank Dr. L. H. Louis, Department of Internal Medicine, University of Michigan, for his help in the preparation of this manuscript.

\section{REFERENCE}

Bierman, E. L., Dole, V. P., and Roberts, T. N. (1957). 'An abnormality of nonesterified fatty acid metabolism in diabetes mellitus', Diabetes, 6, 475-479.

Craig, J. N., and Miller, M. (ig6o), Diabetes, p. 70o. New York: Paul B. Hoeber.

Dole, V. P., and Meinertz, H. (ig6o), 'Microdetermination of long-chain fatty acids in plasma and tissues ', 7 . biol. Chem., 235, 25952599 .

LAurell, S. (1956), 'Plasma free fatty acids in diabetic acidosis and starvation', Scand. $\mathcal{f}$. clin. lab. Invest., 8, 81-82.

Lours, L. H. (1969), 'Lipoatrophic diabetes: an improved procedure for the isolation and purification of a diabetogenic polypeptide from urine', Metabolism, 18, 545-555.

Louis, L. H., and Cons, J. W. (1962), 'Isolation of an insulin antagonist from urine of patient with lipoatrophic diabetes', 7. lab. clin. Med., 60,995 .

Lours, L. H., and Cons, J. W. (1968), 'A diabetogenic polypeptide from hog and sheep adenohypophysis similar to that found in lipoatrophic diabetes ', Metabolism, r7, 475-484.

Louts, L. H., and ConN, J. W. (1969), 'A urinary diabetogenic polypeptide in proteinuric diabetic patients ', Metabolism, 18, 556-563.

Lours, L. H., and ConN, J. W. (I972), 'Diabetogenic polypeptide from human pituitaries similar to that excreted by proteinuric diabetic patients'. Metabolism, 2x, 1-9.

Louis, L. H., ConN, J. W., and Appelt, M. (1971), "Induction of hyperinsulinemia and hyperglycemia in dogs by administration of diabetogenic bovine pituitary peptide ', Metabolism, 20, 326-330.

Louis, L. H., Cons, J. W., and Minick, M. C. (ig63), "Isolation and characterization of an insulin antagonist from urine', Metabolism, 12, $867-886$.

Louis, L. H., Cons, J. W., and Minick. M. C. (1965), 'Isolation of a peptide from bovine adenohypophysis which induces hyperglycemia and insulin resistance in men and dogs, Diabetes, 14, 445 .

Lours, L. H., Cons, J. W., and Minick, M. C. (1966), 'A diabetogenic polypeptide from bovine adenohypophysis similar to that excreted in lipoatrophic diabetes', Metabolism, r5, 309-324.

Louis, L. H., Tutwrler, G. F., and Cons, J. W. (1972), 7. biol. Chem., submitted for publication.

MARcus, R. (1966), 'Retinopathy, nephropathy, and neuropathy in lipoatrophic diabetes', Diabetes, 15, 351-352.

SamaAn, N. A., and Craig, J. W. (1969), ' Failure of stimulation of growth hormone secretion by hypoglycemia in lipoatrophic diabetes ', Metabolism, r8, $460-468$.

TRYGSTAD (1968), "The lipid-mobilizing effect of some pituitary gland preparations, Acta Endocrinologia, 57, 81-107.

Tutwiler, G. F. (1971), 'Influence of bovine diabetogenic peptide, growth hormone, and prolactin on tissue glycogen, liver fat, and liver water of fasting rats', Int. 7 . Biochem., $2,368-$ 370 .

TUTWILER, G. F., and Louis, L. H. (197I), - Glycostatic effect of a diabetogenic nongrowth promoting pituitary polypeptide', Int. 7. Biochem, 2, 319-323.

Key Word Index: Diabetogenic factor, elevated NEFA, beef pituitary, dog, lipoatrophic diabetes. 